\title{
RELAÇÃo DE GÊNERO NA ARTE DA PESCA
}

\section{Aniram Lins Cavalcante; ${ }^{1}$; Monica de Moura Pires²; Guilhardes de Jesus Júnior ${ }^{3}$; Abel Rebouças SÃo JosÉ ${ }^{4}$}

\author{
${ }^{1}$ Doutora pelo Programa de Pós-Graduação em Desenvolvimento e Meio Ambiente da Universidade Estadual de Santa Cruz -UESC. Ilhéus, Babia. \\ Bolsista CAPES. \\ ${ }^{2}$ Doutora do Departamento de Ciência Economia da Universidade Estadual de Santa Cruz -UESC. Ilhéus, Babia. \\ ${ }^{3}$ Doutor do Departamento de Ciências Jurídicas da Universidade Estadual de Santa Cruz - UESC. Ilbéus, Babia. \\ ${ }^{4}$ Doutor do Departamento de Fitotecnia e Zootecnia da Universidade Estadual do Sudoeste da Babia - UESB. Vitória da Conquista, Babia.
}

*Autor para correspondência: anyranlyns@yahoo.com.br

Recebido em 09 de outubro de 2016. Aceito em 05 de março de 2018. Publicado em 14 de abril de 2018.

Resumo - A pesca artesanal tem se mostrado quase que dominada pelo mundo masculino, o que torna a mulher pescadora "invisível" no que diz respeito às relações de poder envolvidas nessa atividade. Tal fato torna relevante compreender e caracterizar as peculiaridades do gênero dentro da pesca artesanal, tomando como cenário de análise, neste trabalho, a Reserva Extrativista de Canavieiras, na Bahia, e, assim, verificar como se estabelecem as relações de gênero na arte da pesca. Utiliza-se a análise multivariada, especificamente a análise de cluster, como instrumento para captar esse fenômeno. Os resultados demonstraram diferenças no perfil econômico relativo ao gênero que se estendem para a atividade pesqueira, revelando o domínio do homem sobre a mulher, tanto nos aspectos sociais de empoderamento quanto na relação com o meio ambiente. Conclui-se que a pesca é onde está claramente definida a atividade de acordo com o gênero; cabe à mulher, portanto, executar tarefas consideradas menos valorizadas econômica e socialmente.

Palavras-chave: Resex; Gênero; Sustentabilidade; Atividade Pesqueira.

\section{GENDER RATIO IN ART FISHING}

ABstract - Small-scale fishing has shown almost restricted to the male world, making the fisherwoman "invisible" regarding the relations of power in this activity. This fact is important to understand and characterize the peculiarities of gender within the artisanal fisheries, taking the Extractive Reserve of Canavieiras in Bahia as scenario for analysis in this study, and thus to verify how the gender relations are established in the art of fishing. Multivariate analysis, specifically the cluster analysis is used as a tool to register this phenomenon. The results showed differences in the economic profile related to the genre, which extend to the fishing activity, revealing the dominance of men over women, both in the social aspects of empowerment and in relation to the environment. It is concluded that fishing is an activity clearly defined according to gender; therefore, it is up to the woman to perform tasks considered economically and socially less valued.

KeYwords: Resex; GENDER; SustainabiLITY; Fishing ACTIVITY.

\section{RELACIÓN DE GÉNERO EN EL ARTE DE LA PESCA}

Resumen - La pesca artesanal se ha demostrado casi restringida al mundo masculino, lo que torna a la mujer pescadora "invisible" en lo referente a las relaciones de poder involucradas en esta actividad. Tal hecho vuelve relevante comprender y caracterizar las particularidades del género dentro de la pesca artesanal, tomando como escenario de análisis, en este trabajo, la Reserva de Extracción Canavieiras, en Bahía, y, así, comprobar cómo se establecen las relaciones de género en el arte de la pesca. Se utiliza el análisis multivariado, específicamente el análisis de conglomerados como instrumento 
para captar este fenómeno. Los resultados demostraron diferencias en el perfil económico relativo al género que se extienden a la actividad pesquera, revelando el predominio del hombre sobre la mujer, tanto en los aspectos sociales de apoderamiento como en la relación con el medio ambiente. Se llegó a la conclusión de que la pesca es la actividad donde está claramente definida la actividad de acuerdo al género; corresponde a la mujer, por lo tanto, realizar tareas consideradas menos valoradas económica y socialmente.

Palabras clave: Resex; GÉnero; Sostenibilidad; Actividad Pesquera.

\section{INTRODUÇÃO}

A atividade pesqueira artesanal é desenvolvida em todo o litoral brasileiro, normalmente em pequenas comunidades, onde recursos extraídos são considerados de uso comum ou bens livres, e cada usuário, atual ou potencial, é capaz de subtrair do acervo que pertence a todos os demais (Pindyck e Rubinfeld, 2010). No entanto, essas comunidades enfrentam grandes problemas: o livre acesso e uso descontrolado dos recursos e a falta de acesso devido à piscicultura e à carcinicultura, à especulação imobiliária, entre outros, os quais podem provocar o desaparecimento de muitas comunidades pesqueiras tradicionais (Cavalcante, 2011). Tais fatos geram a necessidade de regulamentar o acesso a esses recursos antes da sua completa extinção. É nesse contexto que foram criadas, na década de 1990, as Reservas Extrativistas (RESEX) Marinhas, com o desafio de proteger os recursos pesqueiros e as populações tradicionais que os utilizam para sobreviver.

Assim, com a implantação das RESEX Marinhas, o desenvolvimento sustentável começa a se materializar nas comunidades de pesca, equilibrando interesses ecológicos de conservação dos recursos com interesses sociais de manutenção das formas de vida e melhoria de vida e desenvolvimento das populações que ali habitam e fortalecendo a pesca artesanal, evidenciando as demandas e direitos dos pescadores que passaram a participar do gerenciamento dessas unidades de conservação, tornando as decisões nesse universo mais democráticas e participativas.

Entretanto, cabe ressaltar que, não obstante os avanços legislativos e o aumento do número de registros formais de pescadoras, a valorização da pesca artesanal ainda tem se mostrado predominantemente masculina, relacionada principalmente aos pescadores de peixes nobres, a exemplo do camarão e da lagosta. No contexto da pesca, muitas vezes, cabe à pescadora a extração de pescados com menor valor agregado e que, muitas vezes, demandam muito tempo de trabalho para obter volume suficiente para ser comercializado. Isso faz com que a pescadora, inúmeras vezes, seja "invisível" na arte da pesca. Tal fato traz consigo a necessidade de discussões acerca desse tema nos diversos segmentos sociais que envolvem relação de gênero na atividade pesqueira, considerada de domínio masculino. Quando se investiga uma comunidade pesqueira tradicional, percebe-se que a mulher integra-se a esse ambiente com muita naturalidade e realiza a atividade com destreza e harmonia (Cavalcante, 2011; Jesus Júnior, 2014).

A partir desse contexto, neste trabalho, busca-se compreender e caracterizar as peculiaridades do gênero dentro da pesca artesanal na RESEX de Canavieiras, na Bahia, Brasil, tendo como pergunta central: como a mulher pescadora passou a se inserir nesse universo de dominância masculina? Quais são as diferenças e similaridades de gênero apresentadas por esses atores, especificamente nessa unidade de conservação no Sul da Bahia? Assim, o objetivo fundamental do trabalho foi verificar como se estabelecem as relações de gênero na arte da pesca, tomando-se como referência o universo da RESEX de Canavieiras. 
Pressupõe-se que a pesca artesanal esteja alicerçada em um ambiente ainda hostil para aqueles que a exercem, seja pelas práticas da pesca, seja pelas condições socioeconômicas das comunidades, tudo isso em uma dimensão ainda mais forte para a mulher pescadora, que, apesar de uma relação próxima com a natureza e o recurso pesqueiro, como corrobora a teoria ecofeminista, ainda não participa das tomadas de decisões para gestão do seu ambiente e, consequentemente, das políticas especificas que as beneficiem.

Tal situação faz com que as diferenças entre pescadores e pescadoras artesanais estejam fortemente relacionadas à renda obtida da pesca, perpassando por aspectos culturais, sociais e de empoderamento, os quais implicam na dominação do pescador, gerando conflitos de gênero nessa atividade; esses conflitos passam a ser discutidos acentuadamente de forma mais incisiva nas instituições e órgãos envolvidos no mundo da pesca e impulsionam mudanças significativas para as mulheres.

Estado da Arte

A base conceitual deste trabalho assenta-se nos conceitos da sustentabilidade, do desenvolvimento local, feminismo e ecofeminismo, cujos aportes teóricos subsidiam a compreensão dos fluxos relacionais existentes entre os recursos naturais, processos econômicos e interação dos agentes e atores sociais vinculados à pesca artesanal - pescadores e pescadoras. De forma específica, busca-se compreender a relação de gênero dentro da Reserva Extrativista de Canavieiras.

\section{Os Conceitos Básicos Norteadores da Relação de Gênero na Pesca Artesanal}

Os recursos pesqueiros são considerados como recursos de propriedade comum. Segundo Pindyck e Rubinfeld (2010), esses recursos são acessíveis a qualquer indivíduo, no entanto essa conduta inviabiliza a pesca, por torná-la insustentável, devido à sobre-explotação das espécies ali disponíveis. Nesse cenário, a única maneira de controlar a ruína desse recurso é torná-lo um bem privado ou prover a sua regulação pelo governo, induzindo os pescadores ao ótimo desejável.

Assim, para frear essa pressão exacerbada sobre a atividade pesqueira, optou-se pela regulamentação. Dessa forma, foram criadas as primeiras reservas extrativistas marinhas, a fim de permitir a sobrevivência de comunidades que lidam de forma mais direta com os recursos naturais de livre acesso, esses que, muitas vezes, são necessários para o sustento primário.

Essas unidades de conservação são conhecidas por gerenciar de forma distinta os seus recursos, pois adotam gestão participativa ou cogestão, comanejo, cogerenciamento, descrita como um método de gestão formal, que conecta comunidades locais, organizações governamentais e não governamentais, através de um processo colaborativo e participativo de tomadas de decisões regulatórias, entre os representantes dos grupos de usuários - pescadores e pescadoras, agências governamentais, não governamentais, instituições de pesquisa (universidades, institutos), entre outros. Dessa maneira, esse conceito não deve ser considerado fechado, tampouco as decisões gestoras, que devem ser flexíveis à mutação (Kalikoski, 2007).

Esse tipo de gestão deve, assim, propiciar a sustentabilidade local, conforme apontado no Relatório Brundtland publicado em 1987 e largamente difundido pela Comissão Mundial sobre Meio Ambiente e Desenvolvimento, o qual aponta que o desenvolvimento sob a ótica da sustentabilidade não pode fazer com 
que as atividades presentes comprometam o futuro das atividades a serem exercidas nas gerações vindouras, no sentido de esgotar os recursos naturais disponíveis.

Indo além dessa matriz economicista, compreende-se aqui, a partir de (Jesus Júnior 2014), que o desenvolvimento sustentável é aquele que permite a apropriação, utilização e descarte de recursos, satisfazendo as necessidades das atuais gerações sem comprometer esse mesmo processo pelas futuras gerações, integrando e harmonizando as ideias e conceitos relacionados ao crescimento econômico, ao desenvolvimento das capacidades, à justiça social e ambiental, à equidade entre gêneros, à conservação ambiental e à utilização racional dos recursos naturais, para garantia de bem-estar às populações humanas.

Essa construção adota tanto os pressupostos expostos no Relatório Brundtland, que continuam atuais, como a utilização dos recursos para satisfação das necessidades humanas (englobando aí as dimensões econômica, social e ambiental do processo de desenvolvimento), incluindo-se a geração e destinação dos resíduos decorrentes dessa utilização, quanto os entendimentos mais atuais que envolvem o desenvolvimento humano, tais como aqueles relacionados à garantia de bem-estar, participação política, justiça ambiental, equidade geracional, étnica e de gênero.

Nesse sentido, a comprensão do termo desenvolvimento sustentável incorpora a noção de bem-estar do ambiente, das economias e dos povos, e, dessa forma, exige-se uma sinergia em escala global, através da cooperação. Dessa maneira, o desenvolvimento sustentável consiste na integração do desenvolvimento em uma forma de beneficios ao maior número possível de setores econômicos, pessoas e sociedades, atravessando fronteiras e gerações. Assim, deve-se levar em consideração o potencial impacto sobre a sociedade, o meio ambiente e a economia, mantendo em mente que as ações terão impactos em outros lugares e sobre o futuro (Strange e Bayley, 2008).

Cabe ressaltar que esse desenvolvimento deve reforçar os mecanismos de integração dos valores da sociedade, da solidariedade e da união, criando um consenso para manter o desenvolvimento social em equilíbrio, a fim de diminuir os conflitos ou interesses opostos que podem ocorrer nas comunidades pesqueiras foco dessa pesquisa e, assim, interferir no empoderamento das mulheres dessas comunidades. Trabalhos como os de (Jesus Júnior 2014; Alarcon 2014 e Ettinger 2013), realizados nas Reservas Extrativistas Marinhas da Bahia, reforçam a relevância do processo de consolidação da identidade local e como consequência de bases sólidas para o desenvolvimento sustentável das comunidades estudadas.

Nesse contexto, o empoderamento funciona como um mecanismo de propulsão do desenvolvimento, ativando aspectos relevantes para o processo de transformação estrutural e social que exige o desenvolvimento econômico. O empoderamento possibilita a autonomia pessoal e a consciência coletiva, facilitando aindependência e o fortalecimento das estruturas sociais, segundo (Jara 2001), que trata o empoderamento como uma estratégia relevante aos processos de transformação social, definida de diferentes maneiras, mas que, essencialmente, busca o melhor das habilidades individuais e coletivas de uma determinada população local ou grupo, proporcionando às pessoas um maior controle sobre sua própria condição de trabalho e vida. Para o autor, o empoderamento faz com que os indivíduos e os grupos sociais participem ativamente nas ações coletivas que acontecem ao seu entorno. Assim, impulsiona a formação de grupos em comunidades e é capaz de torná-las autônomas e com melhores condições de vida, além de integrar dos excluídos, carentes e demandantes de bens essenciais à sobrevivência, serviços públicos e atenção pessoal (Gohn 2004).

Dessa maneira, a partir do envolvimento da comunidade local, o empoderamento passa a gerar um 
sentimento de pertencimento e identidade local. Segundo (Kaufmann 2004), o termo identidade começa a ser discutido na década de 1960. De acordo com (Melo 2006), a identidade, seja ela regional ou local, é uma construção social que se manifesta a partir das pressões externas ou culturais da sociedade (Lima et al. 2007) enxerga-a de forma mais complexa, a partir de aspectos que variam segundo o período, o local, os valores coletivos e as realidades sociais, ou seja, dos aspectos socioeconômicos presentes em dada comunidade.

Corroborando essa perspectiva, (Pollice 2010) relata que a identidade é uma interpretação específica da relação com determinado lugar, onde a representação da realidade (signos) incide sobre a realidade territorial. Logo, a identidade torna-se mais forte quanto maior for o nível de compartilhamento das relações dos indivíduos existentes, e, assim, maior será o sentido de pertencimento que se constitui a partir da sustentabilidade nas relações transacionais e colaborativas entre o sistema econômico e o campo territorial. Tal relação reforça o valor indentitário e fortalece a comunidade local.

No entanto, se existirem conflitos na relação de gênero, pode ocorrer o enfraquecimento da comunidadelocal. Nesse contexto, é importante destacar que, apesar de o universo da atividade pesqueira ter uma predominância masculina, essa desigualdade entre homens e mulheres concernente aos aspectos sociais e econômicos, entretanto, está sofrendo diminuição em todo o mundo, inclusive na pesca artesanal. Esse fenômeno desvia as mulheres para longe da miséria, permitindo-as enquadrar-se em oportunidades econômicas e políticas antes exclusivas aos homens, levando-as, desse modo, a um protagonismo, quando exercem o seu poder econômico (Larson, 2011).

Nesse contexto, percebe-se que é relevante, especialmente devido ao tema de pesquisa aqui abordado, discutir o papel da mulher e suas relações com a atividade pesqueira e o ambiente que a rodeia, pois exerce papel de "cuidadora" do meio ambiente. Esse fato foi ressaltado na Declaração e Plataforma de Ação de Pequim $(1995)^{1}$.

Dessa forma, é preciso destacar que mulheres exercem a função de consumidoras, produtoras e educadoras e, portanto, são relevantes na promoção do desenvolvimento sustentável (ONU MULHERES, 1995).

Para contextualizar a realidade das mulheres pescadoras, é necessário apontar a evolução do movimento de mulheres no Brasil (feminismo), que se protagoniza em diversas lutas e bandeiras, cujo escopo central é oportunizar igualdade à mulher. São emblemas dessas lutas, pautas e agendas: acesso à educação formal, igualdade salarial, condições dignas de trabalho, direito e controle do próprio corpo e sexualidade. Historicamente, o feminismo ganhou força no Brasil com a criação da Liga para a Emancipação Intelectual da Mulher, em 1919. Posteriormente, essa liga foi transformada na Federação Brasileira para o Progresso Feminista (FBPF), em 1922, que foi sucedida por um período silencioso (Costa, 2005; Caldwell, 2000).

Na década de 1960, ressurge com o golpe militar de 1964, através do feminismo burguês e de organizações de esquerda. Claramente, a opressão vinculada ao governo militar forçou muitas pautas a ingressarem em um recesso forçado ao longo desse período. Esse movimento tem sua visibilidade completamente retomada em 1975, por ocasião da realização do Seminário que discutiu o "Novo" Movimento Feminista, promovido pela ONU no Rio de Janeiro. A proposta foi apresentar o "feminismo moderno", que trouxe indagações sobre a divisão sexual do trabalho e o papel tradicional da mulher na família e na sociedade (Caldwell, 2000).

Apesar de toda essa movimentação, é só a partir de 1984 que as feministas brasileiras começam a organizar encontros de militância, sendo o mais expressivo o III Encontro Feminista Latino-Americano e do Caribe,

1 A Plataforma de Ação de Pequim foi um documento resultante do encontro que aconteceu em Pequim, a Quarta Conferência Mundial sobre as Mulheres, em 1995, com o objetivo de alcançar a igualdade de gênero e eliminar a discriminação contra mulheres e meninas em todo o mundo. (ONU MULHERES, 2015). 
realizado em 1985 na cidade de Bertioga, no estado de São Paulo, com a participação de mais de mil mulheres de diversos estados e países (Costa e Sardenberg, 2008).

Nesse momento, o movimento feminista ultrapassou fronteiras e extrapolou a pressão política na defesa de seus interesses, adentrando o Estado e estabelecendo fortes inter-relações com a sociedade. Inicia-se a inserção das mulheres nos espaços públicos de decisão, como conselhos, secretarias, coordenadorias e ministérios de governo. Essa inserção foi relevante para a elaboração e execução de políticas de gênero. Assim, o feminismo brasileiro articulou-se com outros setores da sociedade para pressionar, fiscalizar e influenciar o aparelho administrativo na definição de metas sociais adequadas aos interesses femininos que garantissem a equidade de gênero (Costa, 2005).

A busca por um maior suporte teórico no âmbito do movimento feminista surge de forma mais intensa na década de 1970 com o ecofeminismo. Siliprandi (2000) representa a escola de pensamento que fornece suporte aos movimentos ambientalistas e feministas, em diversas partes do mundo; esse busca estabelecer um vínculo entre a dominação da natureza e a dominação das mulheres. Já Plumwood (1993) ressalta que o ecofeminismo é a terceira onda do feminismo, sendo, no mundo, considerado um movimento político que representa a disposição das mulheres em se colocar ao lado da natureza contra as formas destrutivas e dualísticas da cultura. No que se refere à atividade pesqueira, observa-se que as políticas de gênero relacionadas ao feminismo são relevantes, na medida em que privilegiam as pescadoras, mulheres que precisam garantir seus direitos, empoderando-se perante suas comunidades.

No trabalho Ecofeminist strategies for change: a case study in western Australia, Schmah (1998) discute e questiona o pensamento ecofeminista de forma mais pormenorizada, conceituando-o como um movimento de desconstrução da realidade. Por isso, busca desconstruir o paradigma cultural ocidental dominante. Esse paradigma dividiu o mundo hierarquicamente em opostos binários: natureza-cultura, mulher-homem, preto-branco, matéria-espírito, emoção-razão, arte-ciência, entre outras. Essa forma de pensamento binário justifica-se na cultura capitalista dominante. Nessa perspectiva, as relações de gênero inserem-se em uma visão patriarcal, em que os homens são considerados superiores às mulheres. Essas crenças associam-se aos aspectos de superioridade ou inferioridade, o que resulta em um mundo capitalista mais cruel, racista e patriarcal e induz a uma perspectiva negativa de pobreza, injustiça e insustentabilidade ambiental.

Para Shiva et al. (1988) e outros autores, a melhor solução é acabar com a dominação patriarcal a partir da desconstrução feminista da epistemologia científica ocidental, que revela os preconceitos e as forças sociais dentro da ciência, os quais refletem a concepção da classe dominante, sexo e dos interesses culturais. Justifica-se essa estrutura dominante pela compreensão de que a atuação feminina é perigosa, sendo necessária a dominação masculina.

Acentua-se, então, a questão fundamental das ecofeministas - a justiça social e a preservação ambiental. Sendo assim, revela-se a necessidade de compreender a dinâmica dos ecossistemas como uma teia de vida com todas as partes igualmente essenciais para o funcionamento saudável do todo. Faz-se necessário, portanto, priorizar a vida na Terra acima dos sistemas econômicos humanos (Schmah, 1998).

Pautando-se nesse contexto, na década de 1990, no ápice da visibilidade social do ecofeminismo, surgiram a Rede de Defesa da Espécie Humana (REDEH), Rede Mulher de Educação (RME) e a articulação internacional Women's Environment e Development Organization (WEDO), que defenderam ações de recuperação do ambiente e trataram algumas das problemáticas femininas na Eco-92 (Siliprandi, 2000). Reforça-se que, do ponto de 
vista econômico, a dominação das mulheres e a exploração da natureza são dois lados de uma mesma moeda, pois são utilizados como recursos naturais sem custos, colocados a serviço da acumulação de capital. Diante disso, a própria visão das mulheres sobre os problemas ambientais inovou as políticas de desenvolvimento, principalmente em relação às populações tradicionais (como as de pescadoras), focando na qualidade de vida e nos valores culturais dessas populações.

Assim, no ecofeminismo, a natureza é compreendida, também, como uma questão feminista, pois ela envolve mecanismos de opressão, subordinação ou dominação, nos quais a mulher, muitas vezes, está inserida (Warren, 2000).

Esse pano de fundo teórico e contextual da militância feminina no âmbito do desenvolvimento sustentável fica mais evidente a partir da análise de (Sen 1987), que explica que desenvolvimento não pode estar divorciado das categorias de gênero e observações específicas relacionadas ao sexo. Segundo ele, as mulheres são vistas cada vez mais, tanto pelos homens como por elas próprias, como agentes ativos de mudança: promotoras dinâmicas de transformações sociais que podem alterar a vida das mulheres e dos homens. Um exemplo disso são as pescadoras da RESEX de Canavieiras, cujo êxito decorrente das mudanças experimentadas por elas não se resume apenas ao bem-estar delas próprias, mas se reflete no cotidiano de suas casas, entre sua família, e também na sua comunidade.

Ressalta-se aqui que os movimentos para desenvolvimento das mulheres pescadoras só obtiveram visibilidade em 2004, na I Conferência Nacional de Pesca, promovida pela Secretaria Especial de Aquicultura e Pesca. Nesse encontro, perceberam que o problema de uma era a dificuldade de todas e, por essa razão, decidiram reivindicar que suas demandas fossem inseridas no documento oficial da Conferência, como resultado dos debates do movimento de mulheres. Infelizmente, somente na II Conferência da Pesca, realizada em 2006, conseguiram alcançar conquistas em suas demandas (Maneschy et al., 2012).

Em decorrência dessas nuances culturais e identitárias e da grande demanda insatisfeita das pescadoras da RESEX de Canavieiras, surge, em 2009, a Rede de Mulheres Pescadoras e Marisqueiras do Sul da Bahia, fruto da união de pescadoras e marisqueiras segundo Cavalcante (2011), com o intuito de dar visibilidade às demandas e necessidades desse grupo, bem como de valorizar a atividade extrativista e pesqueira desempenhada por mulheres. A Rede conta com a participação das pescadoras e marisqueiras de seis municípios (Santa Cruz de Cabrália, Belmonte, Ilhéus, Itacaré, Pedras de Una e Canavieiras) e, desde sua formação, tem o apoio da ONU Mulheres (UNIFEM), além de outros parceiros locais, como a Universidade Estadual de Santa Cruz (UESC). Tal associação buscou tornar as pescadoras visíveis e atuantes dentro da gestão da RESEX de Canavieiras.

Essa realidade é assinalada em trabalho de Jesus Júnior (2015), o qual descreve o processo de formação da Rede e identifica mudanças significativas nas vidas das mulheres que fazem parte dela. Em suas análises, verifica a existência clara de divisão sexual do trabalho na atividade pesqueira de cunho sexista, o qual estabelece um caráter de invisibilidade da participação feminina nessa atividade produtiva, considerando que, nessa visão, a mulher nasceu exclusivamente para o trabalho doméstico e para a reprodução. O patriarcalismo ainda reinante reforça a ideia de que o trabalho desempenhado pela mulher é uma extensão da atividade doméstica. Devido à necessidade de mudar essa realidade e garantir o acesso às políticas públicas de gênero, criou-se a Rede, que começa a inserir suas componentes nos fóruns de discussões de políticas públicas setoriais, além de oportunizar o acesso a benefícios sociais, como: previdenciários, licença-maternidade, seguro defeso, entre outros.

Em face dessa exposição teórico-contextual, pôde-se observar que o conjunto de conceitos aqui discutidos 
constituem-se num aporte teórico relevante para analisar a temática da pesca em suas diversas dimensões, mas, especialmente, quanto às relações de gênero (mulher - homem) e à dinâmica relacional inserida dentro da reserva extrativista selecionada para esta análise.

\section{Material e mÉtodos}

\section{Delimitação da área de estudo}

Este trabalho foi realizado na RESEX de Canavieiras, a qual foi criada pelo Decreto Federal de 5 de junho de 2006. Sua área total compreende 100.687 hectares e abarca parte dos municípios de Belmonte, Una, além do município de Canavieiras, o qual deu o nome à reserva. A maior parte dela está situada em áreas úmidas, e a pesca artesanal é sua principal atividade econômica de cunho extrativista (Cavalcante, 2011).

\section{Procedimentos metodológicos}

As análises tomam como base de dados Cavalcante (2011), que autorizou o seu uso, aprovado pelo Comitê de Ética da Universidade Estadual de Santa Cruz - UESC e pelo Instituto Chico Mendes de Conservação da Biodiversidade - ICMBio. Os dados foram cedidos em planilha de excel. Essa base de dados refere-se a 452 entrevistas realizadas junto a pescadores e pescadoras em 2010. As análises dos dados foram feitas no programa estatístico IBM SPSS Statistics 20.

\section{Análises dos dados}

Inicialmente, são feitas análises descritivas dos dados a fim de retratar as características da atividade pesqueira e, assim, estabelecer relações entre variáveis. Em seguida, a fim de verificar as diferenças e similaridades de gênero na arte da pesca, aplica-se o método de análise multivariada através da análise de agrupamento, também conhecida como análise de cluster.

Esse procedimento compõe-se de cinco etapas, que são: 1 - Critério de parecença/semelhança (similaridade ou dissimilaridade); 2 - Formações dos grupos (escolha do algoritmo de agrupamento); 3 - Definição do número de grupos; 4 - Validação do agrupamento; 5 - Interpretação e análise (Godói, 1985). A primeira etapa consiste na escolha do critério de similaridade ou dissimilaridade, através das medidas de dissimilaridade. A segunda etapa refere-se à escolha do método, que, neste trabalho, seguiu o padrão não hierárquico, também conhecido como método de partição, com $n$ objetos em ke grupos. Parte-se de um número pré-definido de grupos, e, a cada passo, procura-se realocar os objetos de maneira a encontrar a melhor partição, isto é, obter a menor variância dentro do grupo e maior variância entre grupos. Os métodos não hierárquicos geram observações e não variáveis e são mais indicados para amostras grandes (Stuker, 1986). Dentro desse método, o mais utilizado é a k-médias, também escolhido para a análise de gênero desta pesquisa.

$\mathrm{Na}$ terceira etapa, definem-se os k grupos; neste trabalho, foram considerados dois clusters, um que representa o pescador, e outro, a pescadora da RESEX de Canavieiras. Em seguida, foram calculados os centroides. $\mathrm{Na}$ sequência, comparou-se cada elemento do conjunto pela distância euclidiana, e realocaram-se os elementos. Em 
seguida, faz-se a validação dos agrupamentos, a fim de certificar-se nos grupos que são diferentes. Por fim, são feitas as análises de homogeneidade/heterogeneidade em cada estágio do agrupamento, utilizando-se estatísticas descritivas e apresentação de gráficos. As variáveis foram padronizadas em valores de 1 a 4 como critério de parecença (quanto mais próximos ou iguais os valores numéricos, mais similares são os agrupamentos; quanto mais distantes os valores numéricos de um para outro, mais dissimilares são os agrupamentos). Na sequência, as variáveis selecionadas foram se alocando e realocando até encontrar a sua melhor participação; esse processo é denominado de convergência do método.

Neste trabalho, foram analisadas 15 variáveis (Técnica de pesca, Tipos de pescado, Espécies preferidas, Local de pesca, Parceria no trabalho, Repartição dos ganhos da pesca, Escoamento da Produção, Melhoria de vida, Perspectivas por pesca, Filiação em órgão representativo, Forma de participação, Frequência de participação nas reuniões, Pesca versus meio ambiente, Fiscalização ambiental, Renda Mensal).

\section{RESUltados E Discussão}

Em relação ao perfil dos pescadores e das pescadoras da RESEX de Canavieiras, verifica-se que 75\% vivem em união estável e possuem, em média, 39 anos, para ambos os sexos. Apesar de os pescadores apresentarem uma média de idade similar à das pescadoras, eles estão na comunidade há mais tempo, grande parte nasceu nessas comunidades. Em relação ao número de filhos, $50 \%$ das famílias possuem mais de dois filhos, apresentando um perfil populacional de 3,6 filhos por família, número superior à média nacional de 2,3 (IBGE, 2015). Esse número de filhos faz com que, em média, existam 4,2 pessoas vivendo por residência. Além disso, isso faz com que as mulheres, por tradição, passem um período maior de tempo afastadas das atividades remuneradas, sem condições de irem aos locais de pesca extrair seu "sustento", fato que gera também diferenças de renda entre gêneros.

Em relação ao nível de escolaridade e à capacitação profissional, percebem-se semelhanças entre homens e mulheres, ambos têm pouco nível de escolaridade, ou seja, não possuem instrução ou são analfabetos funcionais. Esse mesmo fato foi observado em trabalhos de (Jesus Júnior, 2014 e Alarcon, 2014). Mais de 90\% dos entrevistados possuem apenas o nível fundamental incompleto, resultado também da falta de escolas e infraestrutura nas comunidades; nelas há apenas o ensino fundamental. Nesse sentido, isso se constitui em problemas para o indivíduo no que se refere à mobilidade social dos pescadores e das pescadores e também para a comunidade quanto à sua expansão e desenvolvimento socioeconômico. Isso torna relevante o trabalho exercido de maneira solidária, o qual possibilita maior agregação de valor e a possibilidade de identidade local.

De acordo com os dados, a dimensão econômica apresenta a maior dissimilaridade em relação ao gênero na atividade pesqueira da área estudada. A diferença de renda entre pescadores e pescadoras ocorre em quase todas as dimensões analisadas (Tabela 1), muito semelhante ao observado também em diferentes setores da economia brasileira, até mesmo quando exercem as mesmas funções. Isso evidencia que o mercado de trabalho tem muito o que avançar a fim de tornar igualitária a remuneração entre mulheres e homens.

Ao mesmo tempo, Freitas et al. (2010) destaca que a história da relação entre homens e mulheres vem da divisão sexual do trabalho, que se estabeleceu por meio das mudanças dentro das famílias. Às mulheres cabia a vida privada; aos homens, a vida pública. Assim, o trabalho doméstico era invisível e dizia respeito apenas ao universo feminino. Ademais, a gravidez "retira" temporariamente a mulher do mercado de trabalho, pois é considerada 
a responsável pelo cuidado dos filhos. Essa função também se estende aos demais membros da família, quando esses se encontram impossibilitados ou enfermos. Esses fatos acabam reduzindo as oportunidades de renda da mulher e, muitas vezes, tornam-nas dependentes financeiramente do sexo masculino, e esse acaba exercendo seu domínio sobre o seu destino e o da família.

Tabela1 - Dimensão econômica da atividade pesqueira praticada por pescadores e pescadoras das comunidades da RESEX de Canavieiras, Bahia, 2010

\begin{tabular}{lcc}
\hline DIMENSÃO ECONÔMICA & PESCADOR & PESCADORA \\
\hline Renda mensal com a pesca $^{1}$ & $100 \%$ & $100 \%$ \\
Menos de um salário & 63,6 & 85,9 \\
Um salário & 31,8 & 10,3 \\
Mais de um salário & 4,7 & 3,8 \\
Outros tipos renda $^{2}$ & $100 \%$ & $100 \%$ \\
Temporária $^{2} \%$ & 10,0 \\
Aposentadoria & 39,1 & 66,0 \\
Agricultura & 20,3 & 11,0 \\
Vendedor $_{\text {Benefícios Sociais }}{ }^{3}$ & 15,6 & 12,0 \\
Bolsa escola & 25,0 & $100 \%$ \\
Bolsa família & $100 \%$ & 2,6 \\
Seguro & 1,3 & 59,0 \\
Outros & 10,4 & 10,3 \\
\hline
\end{tabular}

Nota: Qui-quadrado de Pearson p-valor:1=0,000; $2=0,002 ; 3=0,000$.

Neste trabalho, verificou-se que os homens têm uma renda superior à das mulheres, tendo em vista que o produto extraído pela pescadora possui menor preço no mercado. Além disso, o local do trabalho da pescadora, normalmente, é mais próximo da sua casa, o que restringe as possibilidades de obtenção de pescados mais valorizados economicamente. Conforme nota-se na Tabela 1, cerca de 40\% das pescadoras recebiam renda entre 19\% e 38\% abaixo do salário mínimo bruto em 2010 ( $\mathrm{R} \$ 510,00)$, entre $\mathrm{R} \$ 100,00$ e $\mathrm{R} \$ 200,00$; apenas um percentual de 3,5\% conseguia obter uma remuneração acima do salário mínimo.

Por outro lado, mais de 50\% dos pescadores recebiam entre $\mathrm{R} \$ 200,00$ e $\mathrm{R} \$ 400,00$, valor muito superior ao recebido pelas mulheres pescadoras, embora inferior ao salário mínimo de 2010 (Tabela 1). Esses números refletem a baixa remuneração da atividade. Poucos são os que obtêm renda de pelo menos um salário mínimo, independente do gênero. Tal situação tem levado os jovens a saírem dessas comunidades em busca de outras atividades, dada a baixa remuneração e o grande esforço físico exigido sem a adequada contrapartida financeira.

Averiguou-se, também, que $80 \%$ dos entrevistados têm como principal fonte de renda a pesca, e apenas $20 \%$ exercem outras atividades para complementar o rendimento familiar. Nesse sentido, os pescadores exercem atividades temporárias como, por exemplo, a colheita de café em outros estados (39\%), diferentemente das mulheres, que, apenas quando se aposentam (56\%), conseguem ter melhor remuneração, Tabela 1. Tanto a mulher quanto o homem, mesmo exercendo atividades extra-pesca para aumentar a renda, têm relação de identidade com o local, resultado do processo de luta pela criação da RESEX de Canavieiras, conforme aponta (Jesus Júnior 2014).

Nota-se também grande discrepância em relação aos tipos de benefícios sociais, especialmente em relação 
ao Seguro. Como as espécies extraídas pelas mulheres, habitualmente, não são cobertas por esse benefício, elas acabam não tendo acesso a esse tipo benefício, já que a pesca de mar e rio é que se beneficiam, predominantemente, desse seguro. Ressalta-se, entretanto, que algumas pescadoras que compravam o camarão de barqueiros para, então, beneficiar-se e vender conseguiam receber o seguro do camarão. Isso passou a vigorar em 2015, a partir do Decreto $n^{\circ} 8.425 / 15$, o qual foi um grande avanço para o gênero feminino na pesca. Mesmo assim, observase que há diferenças entre a pescadora e o pescador, que ocorrem desde as diferenças de remuneração do que é extraído na RESEX e se expandem para outros níveis, inclusive o de acesso a políticas públicas, a exemplo do seguro defeso.

Além do avanço, anteriormente exposto, o Decreto n ${ }^{\circ}$ 8.425/15 regulamentou o parágrafo único dos artigos 24 e 25 da Lei no11.959/2009, sobre os critérios para inscrição no Registro Geral da Atividade Pesqueira (RGP) e concessão de autorização, permissão ou licença para o exercício da atividade pesqueira. Com isso, foi ampliado o conceito de pescador e pescadora artesanal, ao incluir o exercício da pesca em regime de economia familiar, própria ou em parceria, de forma embarcada ou não. Para além da simples flexão de gênero, a nova norma trouxe uma maior possibilidade de reconhecimento de atividades na arte da pesca, permitindo a regularização de pescadores e pescadoras antes não alcançados pelos conceitos até então utilizados.

Ainda analisando os dados expostos na Tabela 1, resta às pescadoras o Bolsa Família - um programa em nível federal -, que beneficia mulheres com a transferência de recursos para demandas alimentares de crianças em idade escolar e tem permitido a essas mulheres certa "independência" financeira, muito embora o recurso seja apropriado por todos os membros da família.

Outro programa é o Bolsa Verde, criado pela Lei 12.512 de 14 de outubro de 2011, regulamentado pelo Decreto $\mathrm{n}^{\mathrm{o}}$. 7.572, de 28 de setembro de 2011. Como os dados trabalhados neste artigo referem-se ao ano de 2010, tal programa não foi inserido na Tabela 1. Esse Programa constitui-se em um benefício voltado às comunidades tradicionais que vivem em unidades de conservação. Os recursos transferidos às famílias visam ao desenvolvimento de atividades de conservação no local, tendo em vista a limitação de exploração econômica pelas comunidades que lá residem. Assim, o governo federal transfere trimestralmente recurso que é depositado em conta bancária, normalmente para a mulher (pescadora). À exceção do Bolsa Verde e do seguro defeso, todos os demais benefícios sociais aos quais as comunidades pesqueiras têm acesso são políticas voltadas para toda a população do país. Dessa forma, a questão de gênero aqui não é perceptível.

Quando se trata da atividade pesqueira (Tabela 2), verifica-se disparidade relevante em três variáveis analisadas: tipo de pescado ( $\mathrm{p}$-valor 0,000 ), petrechos utilizados na pesca ( $\mathrm{p}$-valor 0,000 ) e área de pesca (p-valor 0,000$)$. Essas variáveis estão diretamente associadas à dimensão econômica, pois retratam o resultado financeiro da pesca, já que os maiores ganhos exigem maior esforço físico e decorrem do tipo de pescado obtido em diferentes áreas de pesca, que, quanto mais distantes (mar adentro ou rio), geram melhor preço no mercado. Assim, o local de pesca afeta a remuneração e o esforço físico despendido, gerando uma relevante desigualdade entre os gêneros e, como resultado, o "domínio" do pescador sobre a pescadora, a qual é, muitas vezes, "coisificada".

Embora muitas delas tenham a ciência desse fato, continuam a extrair sua renda em um ambiente mais próximo de casa, como forma de "proteção" à família. Dessa maneira, poucas são as transformações no universo da pesca, e cabe à mulher um papel secundário, já que seu esforço de pesca fica concentrado na extração de mariscos e crustáceos, oriundos exclusivamente do mangue e que possuem um valor agregado inferior ao dos 
peixes, principalmente de alto mar (Tabela 2).

Esse mesmo resultado foi observado no trabalho de (Di Ciommo 2007), realizado na RESEX Marinha de Corumbau no estado da Bahia, no qual a autora relata a falta de acesso das mulheres a equipamentos e petrechos de pesca, como redes, motores de barcos, equipamentos de segurança (boias e salva-vidas). A autora aponta que as mulheres desempenham atividades produtivas secundárias e consideradas femininas, como beneficiamento do pescado, tarefa socialmente desvalorizada. Como a maioria dessas mulheres não possui outra fonte de renda, isso também implica menor autonomia nas decisões tanto no âmbito familiar como também nas associações representativas da atividade pesqueira.

Tabela 2 - Diferenças na atividade pesqueira em relação ao gênero, RESEX de Canavieiras, Bahia, 2010

\begin{tabular}{lcc}
\hline ATIVIDADE PESQUEIRA & PESCADOR & PESCADORA \\
\hline Tipos de pescado $^{1}$ & $100 \%$ & $100 \%$ \\
Peixe (estuário) & 46,6 & 9,7 \\
Peixe (mar) & 11,5 & 1,9 \\
Marisco/crustáceos & 42,0 & 88,4 \\
Petrecho utilizado na pesca $^{2}$ & $100 \%$ & $100 \%$ \\
Rede, linha, tarrafa (peixes) & 73,9 & 25,0 \\
Siripoia, caniço etc. (mariscos e crustáceos) & 26,1 & 80,0 \\
Área de pesca $^{3}$ & $100 \%$ & $100 \%$ \\
Mangue & 25,3 & 72,3 \\
Rio & 50,2 & 18,1 \\
Mar & 24,2 & 9,6 \\
\hline
\end{tabular}

Nota: Chi-quadrado de Pearson p-valor: $1=0,000 ; 2=0,000 ; 3=0,000$.

Nota-se que a diferença entre pescadores e pescadoras abrange, além da dimensão econômica, a própria atividade pesqueira, revelando o domínio do homem sobre a mulher. Nesse contexto, as mulheres iniciaram um movimento de empoderamento nas suas localidades, tentando obter maior visibilidade.

Para entender o movimento de empoderamento das pescadoras na RESEX de Canavieiras, faz-se necessário examinar a organização social local, que se caracteriza como um dos principais alicerces para o desenvolvimento sustentável nessas comunidades. Essa dimensão do perfil organizacional dos pescadores e das pescadoras pode ser analisada a partir de quatro variáveis: a filiação em órgão representativo de classe, a participação em associação e colônia de pesca, ambas altamente significativas ( $\mathrm{p}$-valor 0,000 ), o tipo de participação (p-valor 0,022 ) e frequência nas reuniões ( $\mathrm{p}$-valor 0,508 ), menos significativas que as primeiras.

Essas variáveis retratam organizações locais sólidas e que podem proporcionar o empoderamento e o fortalecimento das comunidades. Para validar essa informação, é essencial verificar a legitimidade das organizações a partir das seguintes indagações: quais são as instituições locais inseridas (formais ou informais)? Há lideranças comunitárias? Como é a interação na comunidade em que vivem na RESEX de Canavieiras? Verificou-se que as instituições são formais e as lideranças comunitárias são fortes e representativas. Defendem suas localidades nos fóruns, conselhos e nos diversos tipos de reuniões e elaboraram um sistema em que as decisões em relação aos recursos pesqueiros e aos problemas locais são discutidas em reuniões mensais. Em seguida, as decisões são expostas pelo presidente ou representante nas reuniões da Colônia de pescadores Z20, na Associação Mãe dos 
Extrativistas - AMEX e no Conselho Deliberativo da RESEX, promovendo uma gestão participativa na tomada de decisão relacionada ao manejo dos recursos locais.

Constata-se, inclusive, na RESEX estudada que, além de instituições fortes, o modelo de gestão dos recursos pesqueiros e ambientais adota uma gestão compartilhada ou de comanejo do uso dos recursos comuns. Segundo Seixas et al. (2011), esse tipo de gestão decorre da formação de arranjos institucionais diversos, formais e informais, como os existentes na RESEX de Canavieiras. Além disso, com a gestão compartilhada, tem-se a integração dos atores envolvidos no manejo dos recursos pesqueiros, facilitando a promoção da sustentabilidade local e o compartilhamento do poder nas tomadas de decisão dos recursos, segundo aponta (Dumith 2012).

A pesquisa ainda revela que tanto o pescador quanto a pescadora estão organizados e ativos dentro das instituições locais. Todavia, há diferença significativa entre eles quanto à participação em entidade representativa de classe, pois a Colônia possui maior número de homens, enquanto, nas associações, há maior número de mulheres. Tal fato demonstra que as mulheres estão mais vinculadas a representações locais e de base comunitária, o que pode indicar sua preocupação com o espaço em seu entorno, conforme retrata a teoria ecofeminista, enquanto o pescador está mais vinculado a questões mais “abrangentes” no âmbito da política.

Essas diferenças também ajudaram a construir a Rede de Mulheres Pescadoras e Marisqueiras do Sul da Bahia em 2009, composta por cerca de 2000 mulheres, incluindo não apenas os municípios da área abrangente da RESEX de Canavieiras, mas também pescadoras dos municípios de Ilhéus, Itacaré e Santa Cruz Cabrália. Essa Rede permitiu que muitas dessas mulheres fossem para o front da atividade e, desse modo, saíssem do papel de "figurante" para o de protagonista. Isso permitiu, inclusive, que algumas delas passassem a ocupar a presidência de associações, de acordo com (Jesus Júnior 2014), e, assim, fosse ampliado o papel da mulher pescadora na atividade pesqueira local, inserindo-a na tomada de decisões.

Cabe ainda frisar que, em relação à frequência em reuniões, a mulher pescadora é mais participativa e comprometida com o fortalecimento da comunidade local e a valorização da atividade pesqueira; isso revela o empoderamento e a importância que esses espaços de discussão criam em um ambiente tão masculinizado, dando voz às necessidades dessas mulheres. Dessa forma, nota-se que essa é uma transformação na vida dessas mulheres, percepção também constatada em (Jesus Júnior 2014). Acrescente-se a isso que, na criação da RESEX de Canavieiras, houve forte apoio das mulheres das comunidades pesqueiras.

Para verificar de forma mais perspicaz a relação gênero e meio ambiente, foram escolhidas seis variáveis: qualidade de vida, benefícios, perspectiva para pesca, ações para melhoria da atividade, danos ambientais que mais afetam a atividade e problemas que mais afetam o meio ambiente. Apurando-se, as mulheres tiveram maior percepção positiva perante as transformações a partir da implantação da reserva, tanto que 44\% delas relatam melhora na sua qualidade de vida, nos aspectos econômicos e sociais, via acesso a benefícios sociais. São elas que vislumbram melhores perspectivas para a atividade (38\%), enquanto 54\% dos homens acreditam que as condições de pesca irão se agravar com tempo.

As pescadoras apontam que maiores avanços para a atividade ocorreriam a partir de material de pesca, como utensílios de pesca, embarcações etc., mais adequados, além da implantação de uma cooperativa de pesca, que agregaria valor ao pescado e, assim, tornaria o pescado mais competitivo, aumentando a renda e participação no mercado local.

Em relação ao meio ambiente, os pescadores e as pescadoras acreditam que a forma como desempenham a atividade não causam muitos danos ambientais. No entanto, relatam que externalidades como a poluição dos 
rios são o problema mais preocupante, tanto para atividade pesqueira como para a sustentabilidade do ambiente. Similaridades e dissimilaridades entre pescadoras e pescadores

Neste tópico, apresenta-se a análise de agrupamento cluster para compreender melhor a realidade das pescadoras e pescadores da RESEX de Canavieiras.

O número de iterações realizadas atingiu a estabilização após a quinta iteração, isto é, a partir daqui, não ocorreram mais mudanças nos centros dos grupos, e a distância mínima entre os centros iniciais foi de 130,338.

Para visualizar as mudanças ocorridas, tem-se na Tabela 3 a movimentação inicial (centros de clusters iniciais) antes do processo de convergência e os grupos finais consolidados (centros de clusters finais). Dessa forma, o centro dos grupos finais são resultados que permitem conhecer as principais características dentro de cada variável no interior do grupo, como também as similaridades e dissimilaridades mais expressivas em cada grupo para as características analisadas. Na movimentação inicial, o "cluster (1)" é denominado Pescador, e "cluster (2)", pescadora; após as convergências, essas posições alteram-se, o "cluster (1)" passa a ser denominado pescadora, e o "cluster (2)", Pescador (Tabela 3).

Tabela 3 - Movimentação das K variáveis de semelhanças e dessemelhanças entre as distâncias iniciais do centro do grupo "pescador" e do grupo "pescadora e centros de clusters finais da RESEX de Canavieiras, Bahia, 2010

\begin{tabular}{lcccc}
\hline & Centros de cluster iniciais & Centros de cluster finais \\
\cline { 2 - 5 } K- Variáveis & Cluster 1 & Cluster $\mathbf{2}$ & Cluster $\mathbf{1}$ & Cluster $\mathbf{2}$ \\
& Pescador & Pescadora & Pescadora & Pescador \\
& & 2 & 2 & 1 \\
\hline Técnica de pesca & 1 & 2 & 2 & 1 \\
Tipo de pescado & 1 & 2 & 2 & 1 \\
Espécies de maior demanda & 1 & 3 & 3 & 2 \\
Local de pesca & 1 & 2 & 2 & 2 \\
Parceria no trabalho & 3 & 2 & 3 & 2 \\
Repartição dos ganhos da pesca & 4 & 2 & 2 & 1 \\
Escoamento da produção & 3 & 2 & 2 & 2 \\
Qualidade de vida & 2 & 1 & 2 & 2 \\
Perspectivas da pesca & 1 & 2 & 1 & 2 \\
Filiação em órgão representativo de classe & 1 & 1 & 2 & 3 \\
Forma de participação & 2 & 1 & 2 & 2 \\
Frequência nas reuniões & 4 & 2 & 4 & 4 \\
Pesca versus meio ambiente & 4 & 4 & 4 & 3 \\
Fiscalização ambiental & 3 & 1 & 2 & 3 \\
Renda mensal & 2 & & & 2 \\
\hline
\end{tabular}

Na sequência, apresenta-se a Tabela 4, que permite identificar as variáveis que concedem a separação dos grupos, por meio da análise de duas medidas; a primeira, pela variabilidade entre grupos: as variáveis com forte poder de discriminação entre grupos apresentam uma variabilidade elevada entre os grupos, e as variáveis com fraco poder de discriminação entre grupos têm reduzida variabilidade; e a segunda, a variabilidade dentro dos grupos: quanto menor a variabilidade dentro do grupo, maior é o poder explicativo da variável para a constituição dos grupos. Assim, na medida em que F é dado pelo quociente entre essas duas medidas (variabilidade entre grupos/variabilidade dentro dos grupos), quanto maior o valor de F, maior é a contribuição da variável para a definição dos grupos (Tabela 4). 
As maiores diferenças detectadas nos clusters em relação aos pescadores e pescadoras estão expostas nas Tabelas 3 e 4 e na Figura 1. A característica mais expressiva, como retratada na análise descritiva, é a renda mensal, em que se observam claramente as diferenças salariais entre pescadora e pescador. $\mathrm{O}$ teste $\mathrm{F}$, apresentado na Tabela 4, indica que essa é a característica que apresenta a maior discrepância entre os dois casos de clusters (F $=17,365)$.

Tabela 4 - Separação dos clusters a partir da identificação das variáveis utilizadas nas análises de gênero através da ANOVA, RESEX de Canavieiras, Bahia, 2010

\begin{tabular}{lcccc}
\hline \multirow{2}{*}{ ANOVA } & $\begin{array}{l}\text { Cluster } \\
\text { Qédia dos }\end{array}$ & df & F & Sig. \\
\hline Técnica de pesca & 6,459 & 1 & 5,024 & 0,026 \\
Tipos de pescado & 50,937 & 1 & 12,033 & 0,001 \\
Espécies preferidas & 10,082 & 1 & 6,532 & 0,007 \\
Local de pesca & 12,195 & 1 & 7,268 & 0,003 \\
Parceria no trabalho & 0,868 & 1 & 1,503 & 0,222 \\
Repartição dos ganhos da pesca & 10,86 & 1 & 4,517 & 0,035 \\
Escoamento da produção & 0,932 & 1 & 1,045 & 0,308 \\
Renda mensal & 20,912 & 1 & 17,365 & 0,000 \\
Qualidade de vida & 1,413 & 1 & 1,796 & 0,182 \\
Perspectivas da pesca & 0,001 & 1 & 0,003 & 0,958 \\
Filiação em órgão representativo & 0,810 & 1 & 3,444 & 0,065 \\
Forma de participação & 5,674 & 1 & 2,978 & 0,086 \\
Frequência nas reuniões & 9,299 & 1 & 4,872 & 0,028 \\
Pesca versus meio ambiente & 5,857 & 1 & 0,948 & 0,331 \\
Fiscalização ambiental & 0,356 & 1 & 14,263 & 0,000 \\
\hline
\end{tabular}

Nota: Os testes F devem ser usados apenas para finalidades descritivas porque os clusters foram escolhidos para maximizar as diferenças entre os casos em clusters diferentes. Os níveis de significância observados não estão corrigidos para isso e, dessa forma, não podem ser interpretados como testes da hipótese de que as médias de cluster são iguais.

A fiscalização ambiental é a segunda característica mais relevante. Isso pode ter ocorrido, conforme (Cavalcante 2011), pela maior fiscalização da atividade pesqueira após a implantação da RESEX. Isso porque, com as novas regras, as práticas ilegais, como capturar caranguejo de redinha ou na andada, aratu de lanterna, rede de arrasto de malha fina para pesca de camarão, além de outras práticas inadequadas, normalmente realizadas pelos pescadores, passaram a ser proibidas, o que gerou conflitos entre os pescadores e os órgãos de fiscalização. O teste $\mathrm{F}$ apresentou uma dissimilaridade para essa variável ( $\mathrm{F}=14,263)$, Tabela 4. Na Figura 1, pode-se observar como se distribuem as variáveis analisadas entre os dois clusters selecionados nesta análise.

O tipo de pescado apresentou grandes diferenças nas análises de cluster entre os grupos de pescador e pescadora, conforme verificado nas análises descritivas do tópico anterior. Fica evidente a distinção de gênero no que se refere a essa variável, e isso, consequentemente, afeta diretamente a renda, já que os pescados extraídos (peixes) pelo pescador têm valor agregado maior que os capturados pelas pescadoras - mariscos e crustáceos (aratu, siri, ostra etc.), além de maior quantidade de horas trabalhadas para obter um quilo de produto (beneficiamento de mariscos e crustáceos). $\mathrm{Na}$ Tabela 4, verifica-se a dessemelhança apresentada por $\mathrm{F}=12,033$.

Verificam-se também distinções em relação ao local de pesca, pois este está relacionado ao tipo de pescado 
e à renda obtida, $\mathrm{F}=7,268$. Os pescadores deslocam-se para lugares mais distantes de casa, principalmente rio e mar, e as pescadoras concentram-se em áreas próximas à residência, como o mangue.

Figura 1 - Similaridades e dissimilaridades das distâncias entre os centroides finais dos clusters pescador e pescadora da RESEX de Canavieiras, Bahia, 2010

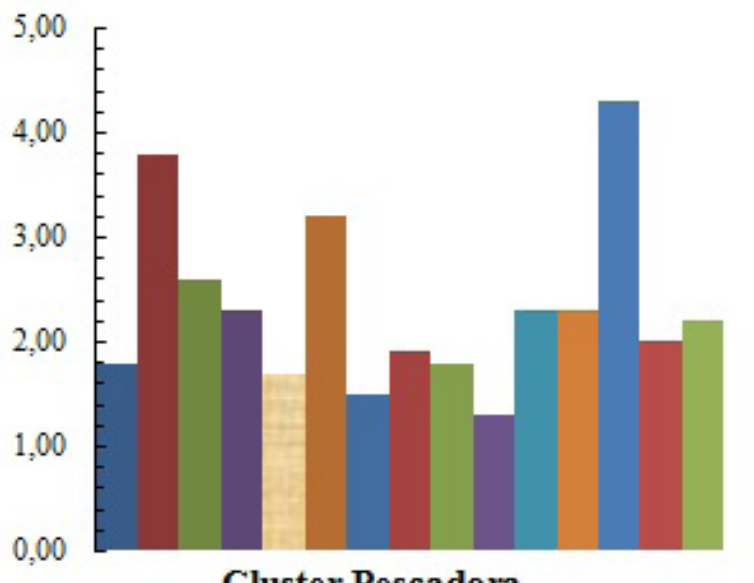

Cluster Pescadora

- Técnica de pesca

Espécies preferidas

- Parceria no trabalho

- Escoamento da produção

- Perspectivas para pesca

- Forma de participação

- Pesca versus meio ambiente

: Renda mensal

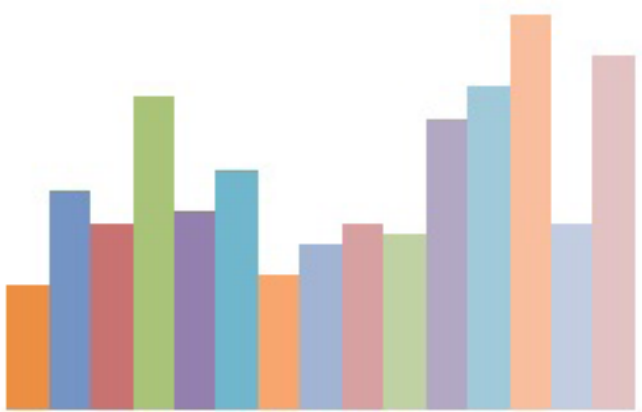

Cluster Pescador

- Tipos pescado

- Local de pesca

- Repartição dos ganhos

- Melhora na qualida de de vida

- Filiação em orgão representativo

* Frequência na participação nas reuniões

- Fiscalização ambiental

As características semelhantes entre pescadores e pescadoras da RESEX de Canavieiras estão relacionadas às perspectivas para a pesca, revelando que, apesar de estarem dentro de uma unidade de conservação, compartilham de uma opinião pessimista em relação à continuidade da atividade pesqueira, sentem-se aflitos e ameaçados pela diminuição do pescado, o teste $F=0,003$, Tabela 4. A segunda variável é a pesca versus meio ambiente, em que ambos apontam a poluição dos rios como um risco múltiplo, tanto para a atividade pesqueira como para o meio ambiente local, $\mathrm{F}=0,948$. A terceira variável refere-se ao escoamento do pescado, pois, independentemente do gênero, há atravessadores locais para fazer com que o pescado chegue até o consumidor, $\mathrm{F}=1,045$. Ambos trabalham, normalmente, em parceria, familiares ou não, e daí apontam a sua existência na arte da pesca $(F=1,503)$, embora seja distinta a repartição dos ganhos oriundos da pesca. Por fim, ressalta-se que os pescadores não perceberam mudanças, transformações ou melhorias após a implantação da unidade de conservação. No entanto, as pescadoras revelaram uma percepção mais positiva, o que pode ter ocorrido em função de sua ampliação nas tomadas de decisão, conforme variável "Qualidade de vida” (F=1,796), Tabela 4.

\section{CoNSIDERAÇõES FINAIS}

$\mathrm{Na}$ atividade pesqueira artesanal, como em diversas atividades econômicas que contemplam homens e mulheres, verificam-se diferenças e similaridades de gênero. Nesta pesquisa, as diferenças entre gênero na RESEX de Canavieiras estão relacionadas principalmente às políticas públicas, evidenciadas pelo acesso a benefícios temporários da pesca (seguro defeso), pois a quase totalidade é acessada pelos pescadores. Além 
disso, a diferença do tipo de pescado acentua ainda mais as diferenças de renda entre pescador e pescadora, pois, em média, ela obtém uma remuneração cerca de 50\% inferior em relação ao pescador.

Apesar dessa situação, a mulher pescadora passou a se inserir nesse universo predominantemente masculino, a partir de transformações relevantes que ocorreram na RESEX, pela maior participação na tomada de decisões nos órgãos representativos da pesca, pela criação da Rede de Mulheres e maior valorização local do seu trabalho. Isso trouxe uma perspectiva positiva para mudanças relevantes e importantes no mundo da pesca local e que pode ser uma experiência importante a ser compartilhada no "mundo" da pesca.

Cabe ressaltar que, apesar da baixa remuneração da atividade pesqueira, percebe-se entre os pescadores e as pescadoras que há uma identidade com o local e que buscam extrair o necessário, a fim de permanecer nas comunidades a partir da pesca artesanal. Esse modo de vida é importante em relação à existência dos recursos pesqueiros e ao ecossistema ao qual pertencem, pois, assim, preservam e conservam esse tipo de ambiente a partir de uma forma sustentável de tratar a natureza.

A atividade pesqueira artesanal necessita de incentivos governamentais a fim de evitar problemas de explotação dos recursos e utilização de práticas de manejo insustentável. Os dados apontam que as perspectivas são positivas para o setor à medida que as pescadoras começam a ocupar posição de mais destaque na atividade e daí, conforme aponta o ecofeminismo, passam a ser protagonistas na sustentabilidade da atividade pesqueira na RESEX de Canavieiras.

\section{Agradecimento}

Projeto financiado pela FAPESB: Fortalecimento de grupos produtivos rurais de comunidades da Reserva Extrativista de Canavieiras, Bahia, sob uma perspectiva de sustentabilidade.

\section{REFERÊNCIAS}

Alarcon DT. 2014. Uso e conservação de recurso pelos pescadores de duas Reservas Extrativistas da Bahia. 2014. 102 f. Tese (Doutorado em Desenvolvimento e Meio Ambiente) - Universidade Estadual de Santa Cruz, Ilhéus, Bahia.

Caldwell KL. 2000. Fronteiras da diferença: raça e mulher no Brasil. Revista Estudos Feministas, 8(2): 91-108. Cavalcante AL. 2011. A arte da pesca: análise socioeconômica da Reserva Extrativista de Canavieiras, Bahia. 2011. 108 f. Dissertação (Mestrado em Desenvolvimento Regional e Meio Ambiente) - Universidade Estadual de Santa Cruz, Ilhéus, Bahia

Costa AAA, Sardenberg CMB. 2008. O Feminismo do Brasil: reflexões teóricas e perspectivas. Núcleo de Estudos Interdisciplinares sobre a Mulher da Universidade Federal da Bahia-UFBA. Salvador-Bahia, Disponível em: <http://articulacaodemulheres.org.br/wp-content/uploads/2015/06/TC-10-NEIM-UFBAO-Feminismo-no-Brasil-1.pdf/>. Acesso em: dez: 2014.

Costa AAA. 2005. O movimento feminista no Brasil: dinâmicas de uma intervenção política. Revista Gênero, 
$5(2): 9-35$.

Declaração e Plataforma de Ação da IV Conferência Mundial Sobre a Mulher. 1995. Instrumentos Internacionais de Direitos das Mulheres. Pequim. Disponível em: < http://www.unfpa.org.br/Arquivos/ declaracao beijing.pdf/>. Acesso em: 14 fev. 2014.

Di Ciommo RC. 2007. Pescadoras e pescadores: a questão da equidade de gênero em uma reserva extrativista marinha. Revista Ambiente \& Sociedade. X (1): 151-163.

Dumith RC. 2012. A importância da gestão compartilhada e das áreas marinhas protegidas para o sistema socioecológico da pesca artesanal: o caso das reservas extrativistas marinhas. Revista GeoTextos. 8 (2): 97-121. Disponível em < $\underline{\text { http://dx.doi.org/10.9771/1984-5537geo.v8i2.6281>. }}$

Ettinger MTM. 2013. Tecendo a rede de mulheres de comunidades extrativistas e pesqueiras do sul da Bahia: reconhecendo e afirmando “ser” mulher. 2013. 136 f. Dissertação (Mestrado em Programa de Desenvolvimento e Gestão Social) - Universidade Federal da Bahia, Salvador, Bahia.

Freitas RCMA. 2010. Construção de uma agenda para as questões de gênero, desastres socioambientais e desenvolvimento. Estudos Feministas, Florianópolis, 16 (3): 889-899. Disponível em < $\underline{\text { http://dx.doi. }}$ org/10.1590/S0104-026X2010000300014>.

Godoi CRM. 1985. Análise estatística multidimensional. 1985. 187f. Tese (Doutorado em Matemática e Estatística) - Universidade de São Paulo - USP, Piracicaba, São Paulo.

Gohn MG. 2004. Empoderamento e participação da comunidade em políticas sociais. Revista Saúde e Sociedade, 13 (2): 20-31.

Instituto Brasileiro de Geografia e Estatística (IBGE). Censo 2010. Disponível em: <http://www.ibge.gov.br/ estadosat/perfil.php?sigla $=\mathrm{df} />$. Acesso em: maio 2015.

Jara CJ. 2001. As dimensões intangíveis desenvolvimento sustentável. Brasília: IICA, 352 p.

Jesus JG. 2014. Mulheres em rede: uma experiência de empoderamento feminino e sustentabilidade ambiental no Sul da Bahia. 2014. 196 f. Tese (Doutorado em desenvolvimento e meio ambiente) - Universidade Estadual de Santa Cruz, Ilhéus, Bahia.

Kaufmann JC. 2004. A invenção de si: uma teoria da identidade. Lisboa: Instituto Piaget. 310 p.

Larson AM. 2011. Decentralization e Forest Management in Latin America: Towards a Working Model'. Public Administration e Development 23(3): 211-26.

Lima JES. 2004. Economia ambiental, ecológica e marxista versus recursos naturais. Revista FAE. 7(1): 119127.

Melo S. 2006. Desarrollo Local e Identidad. In: Identidad, comunidad y desarrollo. Santiago de Chile: Universidad de Chile/ Gobierno de Chile, p. 143-151. 
Mello SCB. 2006. Comentários: o que é o conhecimento em marketing no Brasil, afinal? Revista administração contemporânea. 10(2): 203-212.

Ostrom E. 1990. Governing the commons: The Political Economy of Institutions e Decisions. New York: Cambridge University Press. 294 p.

Pindyck RS, Rubinfeld DLPH. 2010. Microeconomia. 7. ed. São Paulo - SP. 789 p.

Plumwood V. 1993. Feminism e the mastery of nature Feminism for today. London: Routledge, 239 p.

Pollice F. 2010. O papel da identidade territorial nos processos de desenvolvimento local. Revista Espaço e Cultura, 27: p. 7-23. Disponível em < https://doi.org/10.12957/espacoecultura.2010.3539>

Seixas CS. 2011. Gestão compartilhada do uso de recursos pesqueiros no Brasil: elementos para um programa nacional. Revista Ambiente e Sociedade, v. XI, n. 1 p. 23-44 Campinas, São Paulo.

Schmah K. 1998. Ecofeminist strategies for change: a case study in western Australia. Disponível em $<\underline{\text { https: } / /}$ pt.scribd.com/document/253012242/Eco-Feminism>

Shiva V. 1988. Staying Alive: Women, ecology e survival in India. New Delhi: Kali for Women, 233 p.

Siliprandi E. 2000. Ecofeminismo: contribuições e limites para a abordagem de políticas ambientais. Revista Agroecologia e Desenvolvimento Rural Sustentabilidade. 1 (1): 61-70.

Strange TBA. 2008. Sustainable development: linking economy, society, environment. Disponível em $<$ http://www.oecd.org/insights/sustainabledevelopmentlinkingeconomysocietyenvironment.htm>

Stuker H. 1986. Análise multivariada para dados onde a característica observada é subdividida em K classes. 1986. 96 f. Dissertação (Mestrado em Matemática e Estatística) - Universidade de São Paulo, Piracicaba, São Paulo.

Warren KJ. 2000. Ecofeminist Philosophy: A Western Perspective on What It Is e Why It Matters. Maryland: Rowman \& Littlefield Publishers. 253 p. 